\title{
Signos y símbolos judíos en la moneda islámica occidental (siglos II-III/VIII-IX). El caso Idrīsí
}

\author{
Jewish Signs and Symbols in Western Islamic Coinage (II-III / VIII-IX \\ centuries). The Idrīsid case
}

\author{
Almudena ARIZA ARMADA \\ New York University (Madrid Campus) \\ aa90@nyu.edu
}

Recibido: 15 de enero de 2015

Aceptado: 2 de junio de 2015

\begin{abstract}
RESUMEN
En el presente artículo se analiza la huella dejada por los judíos en el numerario idrīsí. Ésta se manifestará tanto a través de una serie de letras, nombres y términos hebreos, como a través de una serie de símbolos monetales. Así pues, en primer lugar, se expone el papel desempeñado por los judíos en tierras del islam y los fundamentos religiosos que condicionaron su labor como orfebres y acuñadores de moneda. En segundo lugar, se analiza el caso Idrīsí: el papel desempeñado por las tribus judías en la explotación minera y en la acuñación de moneda, así como los signos y símbolos que dejaron grabados en el numerario. Se analiza también la posible influencia que pudieron recibir los símbolos de la moneda idrīsí de los que encontramos en la moneda omeya oriental, y su probable carácter judáico.

Palabras clave: Marruecos, Idrīsíes, judíos, símbolos judíos, letras hebreas, símbolos omeyas, palmera, minas, matriarcado, bereberes, Mrīra, Tudga, İkam, al-'Alīya, Walīla, Wațịṭ, Wazeqqūr.
\end{abstract}

\begin{abstract}
This article analyzes the traces left by the Jews on the Idrisid coinage. These traces will be evident in a group of letters, names and Hebrew terms as well as on a few different monetary symbols. First, I will expose the role played by Jews in Muslims lands and the religious ideas that conditioned their work as metalworkers and coin minters. Secondly, I will analyze the Idrisid case: the role of the Jewish tribes in mining and in the manufacture of coins as well as the signs and symbols that they reproduced on their coins. In addition, I will also analyze the possible influence that the symbols found on the eastern Umayyad could have had on the Idrisīd coinage and its possible Jewish origin.

Keywords: Morocco, Idrisīds, Jews, Jewish symbols, Hebrew letters, Umayyad symbols, Palm tree, Mines, Matriarchy, Berbers, Mrīra, Tudga, İkam, al-‘Alīya, Walīla, Wațịṭ, Wazeqqūr.

SUMARIO: 1. Introducción, 2. Los judíos y la fabricación de moneda en Dār al-Islām. Fundamentos religiosos, 3. Los judíos y la moneda en el Magrib al-Aqșā (siglos II-III/VIII-IX): los Idrīsíes y sus contemporáneos, 4. Los judíos y la explotación minera en Marruecos durante el período idrīsí, 5. Signos y símbolos hebreos en la moneda idrīsí y de sus contemporáneos, 5.1. Letras aisladas, 5.2. Nombres propios, 5.3. Otros términos hebreos, 5.4. Otros símbolos, 6. Conclusiones
\end{abstract}




\section{INTRODUCCIÓN}

El presente artículo pretende ser una primera aproximación a un tema que la historiografía española no ha abordado hasta la fecha: el papel desempeñado por los judíos en la moneda islámica. Éste es, pues, el primero de una serie de trabajos acerca de los judíos y la moneda islámica en los que se irá profundizando, entre otros, en varios de los temas aquí planteados, así como en nuevos aspectos relacionados.

Tras exponer los fundamentos que condicionaron la dedicación de los judíos a la orfebrería y a la acuñación monetal, abordaré la relación de los judíos con la dinastía idrīsí y el papel que desempeñaron en la explotación minera y en la acuñación de moneda. A continuación, analizaré la huella que las tribus judías magrebíes dejaron en el numerario idrīsí y en el de sus contemporáneos: letras aisladas, nombres propios y términos hebreos. Por último, analizaré algunos símbolos monetales desde la perspectiva de su probable carácter judaico, así como la posible influencia que pudieron recibir de la moneda omeya oriental.

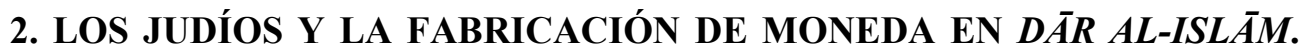 FUNDAMENTOS RELIGIOSOS}

Desde el origen mismo de la moneda islámica, los judíos desempeñaron un notable papel en la acuñación monetal como monederos en Dār al-Islām ${ }^{1}$. El hecho de que los musulmanes emplearan a judíos en la fabricación de moneda no fue algo arbitrario o casual sino debido, en gran medida, a razones de índole religiosa, y en concreto a la prohibición de la usura $(r i b \bar{a})$, claramente prohibida y condenada en tres aleyas coránicas:

¡Vosotros que creéis! No os alimentéis de la usura, que se multiplica sin fin, y temed a Allāh para que podáis tener éxito. ${ }^{2}$

Y por haber adoptado la usura que ya les estaba prohibida, y haber usurpado los bienes de los hombres con falsedad.

Hemos preparado para los que de ellos hayan caído en la incredulidad un castigo doloroso ${ }^{3}$.

Y lo que deis de más para que se os revierta aumentado en la riqueza de la gente, no crecerá junto Allāh.

Pero lo que deis con generosidad buscando la faz de Allāh... A ésos se les multiplicará ${ }^{4}$

\footnotetext{
${ }^{1}$ Sirva como ejemplo, entre varias, la afirmación de Eustache: «Les Juifs jouèrent un grand rôle dans le domaine de la monnaie sur tout le territoire de l'Islam. [...] ils en vinrent à détenir le monopole technique » (EUSTACHE, Daniel, "La question des monnaies [Extrait du Kitāb Futūh el-Buldān d'Abū l-Abbās Aḥmad Ibn Yaḥyà Ibn Ğābir el-Bag̉dādī, connu sous le nom d'el-Balādurīi]”, HespérisTamuda, IX, 1 (1968), 74-107, 98).

${ }^{2}$ Corán III, 130.

${ }^{3}$ Corán IV, 160. Al hilo de la condena de ciertas actitudes de los judíos.

${ }^{4}$ Corán XXX, 38. El término en árabe para la expresión "deis de más" es ribā. Por tanto, la aleya hace alusión al interés usurario. Sin embargo, para algunos comentaristas, en este caso se refiere a los
} 
Con el tiempo, la prohibición de la usura se fue desarrollando gradualmente en la legislación islámica, produciéndose diversas interpretaciones, más o menos rígidas, según las diferentes escuelas jurídicas 5 . La mayor parte de las tradiciones prohíben expresamente el intercambio de cantidades diferentes de una misma cosa pero de diferente calidad. Otras exigen igualdad de cantidad incluso en la venta de metales preciosos manufacturados. En algunos casos, incluso, se ha llegado a considerar que el intercambio de las mismas cantidades de las mismas cosas, especialmente si se trata de metales preciosos, es usura. A ello hay que añadir el hecho de que el oro y la plata son considerados generalmente bienes capaces de riba $(m \bar{a} l \text { ribawi })^{6}$. Todo ello implica que cobrar más por un producto de orfebrería que por lo que se cobraría por el material precioso es considerado usura. Así mismo, las monedas de oro y plata son $m \bar{a} l$ ribaw $\vec{\imath}$. Por tanto, la fabricación de monedas de oro y plata no sólo supone una alteración del valor de la materia preciosa que las conforman, sino que el hecho en sí constituye un riesgo de usura ${ }^{8}$. Riesgo del que se previene incluso en algunos tratados sobre la fabricación de moneda. Sirva, como ejemplo, la siguiente referencia relativa al período aglabí: “...si l'on laisse les Juifs [salvo que sean dignos de confianza por su lealtad, reputación y buenas costumbres] et les Musulmans tiedès s'occuper (...), l'usure se développe, les monnaies se corrompent, les procès et les difficultés se multiplient".

intereses o beneficios permitidos de una transacción, como pueda ser la entrega de más esperando un beneficio a cambio, que si bien no es ilícito, no tiene recompensa alguna antes Dios. (Cf. la nota a la aleya en la versión de El Corán editada por el Complejo del rey Fahd para la edición del Noble Corán en Medina al-Munawwara, 1417 H., traducción y comentario por Abdel Ghani Melara Navio, 667).

5 "Ribā" en Encyclopaedia of Islam, Second Edition. [En línea] P. Bearman, Th. Bianquis, C.E. Bosworth, E. van Donzel, W.P. Heinrichs (Eds). Brill Online, 2014. Disponible en: http://referenceworks.brillonline.com/entries/encyclopaedia-of-islam-2/riba-COM_0918 [Último acceso 05 de diciembre de 2014]. Véase también: MAILLO SALGADO, Felipe, Vocabulario de historia árabe e islámica, Ed. Akal, Madrid, $2^{\circ}$ ed. 1999, 201; VERCELLIN, Giorgio, Instituciones del mundo musulmán, (1ºd. Roma 1996), Eds. Bellaterra, Barcelona, 2003, 285-286; CHOUDHURY, Masudul Alam, "Usury" en Encyclopaedia of the Qur'ān, [En línea] General Editor: Jane Dammen McAuliffe, Georgetown University, Washington DC. Brill Online, 2014. Disponible en:

http://ezproxy.library.nyu.edu:3553/entries/encyclopaedia-of-the-quran/usury-EQSIM_00438 [Último acceso 05 de diciembre de 2014]. Sobre la prohibición de la usura en el judaísmo: YEHUDA, Don, "Economics, Judaism and" en Encyclopedia of Judaism, Leiden: Brill, 2005. [En línea]

Disponible en:

https://login.library.nyu.edu/ezproxy?institute=NYU\&url=http $\% 3 \mathrm{a} \% 2 \mathrm{f} \% 2 \mathrm{fsearch} . c r e d o r e f e r e n c e . c$ om $\% 2$ fcontent $\% 2$ fentry $\% 2$ fbrilljud $\% 2$ feconomics_judaism_and $\% 2$ f0 [Último acceso 30 de diciembre de 2014]

6 "Ribā" en Encyclopaedia of Islam...

${ }^{7}$ Excepcionalmente, se incluyen incluso las monedas de poco valor ("only quite exceptionally are coins of small denomination included") Ibidem.

${ }^{8}$ El mayor o menor grado de aplicación en la práctica del concepto de ribā a la acuñación de moneda debe analizarse en cada caso concreto, pues lógicamente, no fue el mismo en todas las épocas y territorios del islam, ni tiene igual consideración en las diferentes escuelas jurídicas, como ya he indicado.

${ }^{9}$ BRETHES, Joseph Dominique, Contribution à l'histoire du Maroc par les Recherches Numismatiques, Casablanca 1939, 266. 
Por tanto, el trabajo de la orfebrería y, en cierta medida, el de la acuñación de moneda llegaron a convertirse así en oficios característicos de los no musulmanes en los territorios de Dār al-Islām, hasta entrado el siglo XIV/XX, llegando a estar vedado el trabajo de los metales nobles a los musulmanes, en épocas y lugares, como es el caso del Fez del siglo XVI, según el testimonio de León El Africano:

... à Fèz on ne peut travailler (...) ni l'or ni l'argent dans la vieille ville et aucun mahométan ne peut exercer la profession d'orfèvre car on dit que vendre les objets d'argent ou d'or pour un prix supérieur à ce que vaut leur poids est de l'usure (ce que l'islam interdit). Mais les souverains donnent aux Juifs la permission de le faire ${ }^{10}$.

De hecho, como las fuentes árabes indican, las primeras monedas islámicas de plata (dirhames), fueron realizadas por un monedero judío, originario del oasis de Taymā' en Arabia, llamado Sumayr, durante el gobierno del califa omeya 'Abd alMalik Ibn Marwān (65-86/685-705) ${ }^{11}$.

Sin embargo, la fabricación de moneda, como el resto de las actividades de los judíos, estuvo condicionada por su calidad de dimmíes, y como en tantos otros aspectos de la vida social, marcada por una serie de limitaciones. De hecho, uno de los ejemplos más conocidos ${ }^{12}$ que ilustran lo desaconsejado de que un judío, en su condición de dimmí, ocupe un puesto público en el estado islámico, hace referencia precisamente a la cuestión de la legitimidad del nombramiento de un judío como inspector de monedas:

PREGUNTA: Un judío ha sido nombrado inspector de monedas en el tesoro de los musulmanes para pesar los dirhams que van y vienen y examinarlos, y se deposita confianza en él para este cometido. ¿Es tolerable este nombramiento según la Ley Santa o no?, ¿recompensará Dios al gobernante que le despida y sustituya por un musulmán competente?, ¿será también recompensado por Dios el que ayude a que sea despedido?

${ }^{10}$ GOLDENBERG, André, L'Art chez les Juifs du Maroc, Somogy Éditions d'Art, Paris, 2014, 36. Véase también, por ejemplo: FLOOR, Willem en "Artisans, Iran", Encyclopaedia of Islam, THREE. [En línea] Kate Fleet, Gudrun Krämer, Denis Matringe, John Nawas, Everett Rowson (Eds.), Brill Online, 2014. Disponible en: http://referenceworks.brillonline.com/entries/encyclopaedia-of-islam3/artisans-iran-COM_23765. [Último acceso 05 de diciembre de 2014]. Para el caso de Marruecos: LÉVY, Simon, Essais d'histoire et de civilisation judeo-marocaines, Centre Tarik Ibn Ziad, Rabat, 2001, 34 y 98-101; ZAFRANI, Haïm, Deux mille ans de vie juive au Maroc. Histoire et culture, religión et magie, Maison-neuve \& Larose, 1998, 151-155; y ZAFRANI, Haïm, Le judaisme maghrébin. Le Maroc terre de rencontres, des cultures et des civilisations, Editions Marsam, Rabat, 2003, 227237; CÉLÉRIER, Jean, "Une mission universitaire au Maroc", Annales de Géographie, 1924, t. 33, $\mathrm{n}^{\circ} 183,197-233,218$.

${ }^{11}$ EUSTACHE, Daniel, "La question des monnaies...", 80; WASSERSTEIN, David J., "Sumayr" en Encyclopedia of Jews in the Islamic World. [En línea] Executive Editor Norman A. Stillman. Brill Online, 2014. Disponible en:

http://referenceworks.brillonline.com/entries/encyclopedia-of-jews-in-the-islamic-world/sumayrSIM_000491 [Último acceso 05 de diciembre de 2014].

${ }^{\overline{1}}$ Lo recoge, por ejemplo, Lewis en su clásico Los judios del Islam (LEWIS, Bernard, The Jews of Islam, Princeton University Press, 1984. Trad. española: Los judios del Islam, Letranúmero, Madrid, 2001/2, 40-41). 
RESPUESTA: No es tolerable nombrar a un judío para ese puesto, no se le puede dejar en él, no es tolerable confiar en su palabra para ningún asunto que tenga relación con el mismo (p. 41). El gobernante, Dios asegure su éxito, será recompensado por despedirle y sustituirle por un musulmán competente, y cualquiera que ayude a su despido será recompensado. Dios dijo: " $; O$ Oh los que creéis! No toméis confidentes fuera de vosotros, porque no escatimarán, no os perdonarían defecto, pues aman lo que os entristece; el odio aparece en sus bocas y lo que ocultan sus pechos es mucho peor. Os hemos aclarado las aleyas si razonáis (Corán III, 14). Esto significa que no se detendrán ante nada para lastimaros y causaros daño y dolor. "El odio aparece en sus bocas", puesto que dicen "Nosotros somos vuestros enemigos"13.

No obstante, como es bien sabido, en la práctica los judíos llegaron a ocupar altos cargos públicos, y en mayor medida, medios y bajos cargos. En lo que a la moneda se refiere, aunque hay varias noticias en las fuentes árabes relativas a judíos que desempeñaron la función de acuñadores, no tenemos constancia de que ninguno de ellos llegara a ser director de la ceca (șạhib al-sikka). Su trabajo debía ser fundamentalmente manual, y por tanto, bien realizarían la labor de fundidores (sabbākūn),

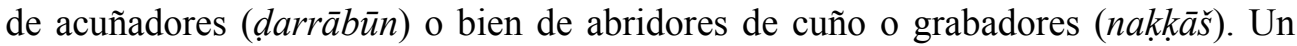
ejemplo de ello podemos encontrarlo en el tratado de técnica monetaria Al-așdāf almunfaḍda, datado a finales del siglo X/XVII, donde se indica que le ensayador bien podía ser un musulmán piadoso o bien un dimmí hábil, astuto y que tuviera una buena conducta con sus correligionarios ${ }^{14}$. Las distintas funciones que llevaron a cabo los judíos en la Dār al-Sikka fueron diferentes según las épocas y las diversas dinastías bajo las que desarrollaron su labor ${ }^{15}$. En el caso del actual Marruecos, los

${ }^{13}$ LEWIS, Bernard, Los judios..., 41 citando a al-Nawāwī, al-Manțūrāt, ed. I. Goldziher, REJ 28 (1894), 94; traducción inglesa en Lewis, Islam, II, 228-229.

${ }^{14}$ BEN ROMDHANE, Khaled, "Traité inédit de technique monétaire", Revue Numismatique, 30 (1988), 207-226, 218. Aunque en este punto del texto en concreto se utilice el término dimmí, en otros pasajes se refiere explícitamente a los judíos. Hay que indicar, así mismo, que al tiempo que se señala la habilidad técnica de algunos refinadores judíos, en este tratado también se advierte o previene, en línea con la cita anterior respecto al nombramiento de un judío como inspector de monedas, del hecho de que los judíos que trabajan en la fábrica de la moneda tienen la oportunidad de sustraer los metales preciosos (Cf. Ibidem, 224). Por otro lado, el hecho de que los judíos tuvieran que grabar en los cuños monetales textos coránicos y fórmulas religiosas islámicas no debió ser un problema, dado que es sabido que los judíos que trabajaban en puestos de la administración usaban las fórmulas islámicas con normalidad, siendo el paradigma de ello el caso de Samuel Ibn Naghrela, quien, según Ibn Hayyān, "He used the usual Islamic formulas, the eulogies of God and Muhammad, our Prophet, and recommended to the addressee to live according to Islam. In brief, one would believe that his letters were written by a pious Muslim". (Cf. BRANN, Ross, "Textualizing Ambivalence in Islamic Spain: Arabic Representations of Ismail Ibn Nagrilah" en R. Brann (ed.) Languages of Power in Islamic Spain, CDL Press, Bethesda, Maryland, 1997, 107-135, 114-115).

${ }^{15}$ LACHMAN, Samuel, "Jews and the Mints of Islam" en The Shekel, XIX, 4 (1986), 10-12, 11; "Dār al-Ḍarb" en Encyclopaedia of Islam, Second Edition. [En línea] P. Bearman, Th. Bianquis, C.E. Bosworth, E. van Donzel, W.P. Heinrichs (Eds). Brill Online, 2014. Disponible en: $\mathrm{http} / / /$ referenceworks.brillonline.com/entries/encyclopaedia-of-islam-2/da-r-al-d-arb-COM_0150. [Último acceso 05 de diciembre de 2014]. 
judíos fueron joyeros y acuñadores de monedas, y realizaron su labor supervisados por los ulemas ${ }^{16}$.

\section{LOS JUDÍOS Y LA MONEDA EN EL MAGRIB AL-AQȘĀ (SIGLOS II- III/VIII-IX): LOS IDRĪSÍES Y SUS CONTEMPORÁNEOS}

Aunque el tema es conocido, al menos desde la publicación de Eustache de su Corpus des dirhams Idrīsites et contemporains ${ }^{17}$, parece haber pasado desapercibido para los pocos especialistas que han tratado el tema ${ }^{18}$.

Con la llegada de Idrīs I a Marruecos huyendo de la persecución 'abbāsí, los judíos tuvieron un papel significativo en la lucha frente al califa de Bagdad, combatiendo junto al descendiente del Profeta. Pero tras la victoria idrīsí, surgió el enfrentamiento y muchas tribus judías se negaron a aceptar la autoridad de Idrīs I y la conversión al islam ${ }^{19}$. Así, una vez hubo instalado su campamento militar en la orilla derecha del río Fās, Idrīs I llevó a cabo una serie de expediciones militares para asegurar su autoridad sobre las tribus vecinas, la mayoría de las cuales eran cristinas, judías o profesaban religiones animistas. Otras eran jāriŷíes ${ }^{20}$. De hecho, la leyenda monetal extraída del Corán XVII, $105^{21} \breve{G a}$ 'a l-haqqu wa zahuqa l-bātiliu, 'inna l-bātila kana zahūqā ("La Verdad ha llegado, el Error se ha disipado. El error debe disiparse"), que introdujo Idrīs I en sus monedas como leyenda marginal y que figurará también en las acuñadas a nombre de Idrīs II hasta el final de la regencia (192/807-808) y durante su imāmato hasta el año 195/810-811, se ha considerado una alusión al esfuerzo idrīsí de extender el islam frente a los judíos, cristianos, animistas y frente a los jāriŷíes ${ }^{22}$.

${ }^{16}$ La supervisión por parte de los ulemas del trabajo de los metales llevado a cabo por judíos está documentado al menos para el caso de Fez, además de estipulado en los tratados anteriormente mencionados. Cf. DESHEN, Shlomo, Les gens du Mellah. La vie juive au Maroc à l'époque pré-coloniale, Albin Michel, Paris 1991, 77; TEDGHI, Joseph, "Fez" en Encyclopedia of Jews in the Islamic World. [En línea] Leiden: Brill, 2010. Disponible en: http://ezproxy.library.nyu.edu:12765/content/entry/brilljiw/fez/0 [Último acceso el 22 de diciembre de 2014].

${ }^{17}$ EUSTACHE, Daniel, Corpus des dirhams Idrīsites et contemporains. Collection de la Banque du Maroc et autres Collections Mondiales, publiques et privées, Banque du Maroc, Rabat, 1970-1971.

${ }^{18}$ Por ejemplo, Lachman, en su serie pionera de artículos sobre los judíos de las cecas del Islam no se refiere a las emisiones idrīsíes en su trabajo dedicado a la Península Ibérica y el Norte de África (LACHMAN, Samuel, "Jewish Minters in some Mints of the Islamic West" en The Shekel, XXI, 1 (1988), 18-20).

${ }^{19}$ BENSABAT, Salomón J., "Los judíos en Marruecos", Cuadernos de estudios africanos, 17 (1952), 37-48. Reeditado en Los sefardies del norte de Marruecos, un puente con España. Música, religión y cultura, Comunidad Judía de Madrid, Madrid 2003, 17-32, 18-20; ISRAEL GARZÓN, Jacobo, Los judios hispano-marroquies (1492-1973), Hebraica Ediciones, Madrid 2008, 23.

${ }^{20}$ EUSTACHE, Daniel, Corpus des dirhams Idrīsites..., 25.

${ }^{21}$ EUSTACHE, Daniel, Corpus des dirhams Idrīsites..., 63 indica que procede de Corán XVII, 18 pero no se corresponde. Más bien parece responder a la aleya 105.

${ }^{22}$ EUSTACHE, Daniel, Corpus des dirhams Idrīsites..., 63. 
Una vez sometidas a su autoridad las tribus judías, Idrīs I impuso el estatuto de la dimma, que regularía la relación de los judíos magrebíes con el nuevo poder islámico. Así, durante el gobierno de Idrīs II, muchos judíos se instalaron en Fez, donde llegaron a constituir un segmento importante de la población. Aunque se desconoce el número exacto de judíos que habitaban la ciudad en el período idrīsí, éste debió ser numeroso si tenemos en cuenta que la recaudación obtenida del impuesto de capitación (ŷizya) ascendía a 30.000 dinares $^{23}$. Los judíos, instalados en la zona norte de la ciudad, jugarían a partir de este momento un significativo papel en el desarrollo del núcleo urbano, manteniendo una importante actividad artesanal, comercial e intelectual. En Fez, se crearían destacadas escuelas talmúdicas y rabínicas, convirtiéndose la capital idrīsí en un centro intelectual, del que saldrán figuras de la talla de Mar Shelomó Ben Dayán Ben Formas, Yacob Hacohen Alfasi, Samuel Hacohen ibn Yoshiyahu, Hofni Hacohen ${ }^{24}$ y en los siglos siguientes personalidades como Judah ibn Quraysh ${ }^{25}$, Dunash ben Labrat ${ }^{26}$, Judah Hayyūj ${ }^{27}$ o Isaac al-Fās $\overline{1}^{28}$.

En Fez, los judíos se dedicarán a la fabricación de moneda y aunque no he podido localizar por el momento información específica en las fuentes árabes al respecto durante el período idrīsí, sí están traducidos y publicados algunos documentos judíos del siglo XVIII que ofrecen una importante información al respecto. Aunque no sean contemporáneos de las monedas que nos ocupan, pueden ilustrar por analogía una actividad, la del trabajo de los metales (oro, plata, piedras preciosas y perlas finas) por parte de la población judía, y en concreto la fabricación de

${ }^{23}$ SCHROETER, Daniel, TSUR, Yaron, HATIMI, Mohammed, "Morocco" en Encyclopedia of Jews in the Islamic World. [En línea] Executive Editor Norman A. Stillman. Brill Online, 2014. Disponible en: http://ezproxy.library.nyu.edu:3553/entries/encyclopedia-of-jews-in-the-islamicworld/morocco-COM_0015720 [Último acceso 22 de diciembre de 2014].

${ }^{24}$ ISRAEL GARZÓN, Jacobo, Los judios hispano-marroquies..., 24.

${ }^{25}$ MAMAN, Aharon, "Ibn Quraysh, Judah" en Encyclopedia of Jews in the Islamic World. [En lí-

nea] Executive Editor Norman A. Stillman. Brill Online, 2014. Disponible en: http://referenceworks.brillonline.com/entries/encyclopedia-of-jews-in-the-islamic-world/ibnquraysh-judah-SIM_0011020 [Último acceso 30 de diciembre de 2014].

${ }^{26}$ MARTÍNEZ DELGADO, José, "Dunash ben Labrat ha-Levi” en Encyclopedia of Jews in the Islamic World. [En línea] Executive Editor Norman A. Stillman. Brill Online, 2014. Disponible en: http://referenceworks.brillonline.com/entries/encyclopedia-of-jews-in-the-islamic-world/dunashben-labrat-ha-levi-COM_0006790 [Último acceso 30 de diciembre de 2014].

${ }^{27}$ MARTÍNEZ DELGADDO, José, "Ḥayyūj, Judah (Abū Zakariyyā Yaḥyā) ben David al-Fāsi”" en Encyclopedia of Jews in the Islamic World. [En línea] Executive Editor Norman A. Stillman. Brill Online, 2014. Disponible en: http://referenceworks.brillonline.com/entries/encyclopedia-of-jews-inthe-islamic-world/h-ayyu-j-judah-abu-zakariyya-yah-ya-ben-david-al-fa-si-COM_0009580 [Último acceso 30 de diciembre de 2014].

${ }^{28}$ CHWAT, Ezra, "al-Fāsī, Isaac ben Jacob" en Encyclopedia of Jews in the Islamic World. [En línea] Executive Editor Norman A. Stillman. Brill Online, 2014. Disponible en:

$\mathrm{http} / / /$ referenceworks.brillonline.com/entries/encyclopedia-of-jews-in-the-islamic-world/al-fa-si-isaacben-jacob-COM_0001310 [Último acceso 30 de diciembre de 2014]. 
moneda, que quedó tradicionalmente consolidada en el actual Marruecos ${ }^{29}$. En un texto de $1751^{30}$ se afirma que el rey confía la Casa de la Moneda (dār al-sikka) a comerciantes cristianos, dándoles la libertad de contratar a su criterio a los trabajadores de la ceca. Los comerciantes cristianos contrataron a tres judíos, Joseph, Moïse y Mardochée, como fundidores y grabadores de cuño de las monedas de plata. Los tres monederos se asociaron, regulando su relación mediante un acta fechada el 23 de Adar de 5506/1746, de la que se entregó copia a los comerciantes cristianos. En el acta de asociación se convenía que los tres repartirían equitativamente lo ganado en la dār al-sikka, pero siendo de beneficio propio lo que ganaran por acuñar en su tiempo libre. Una taqqanah de 1750, ante la circulación de monedas de mala ley, prohibía a todos los judíos acuñar dinares y piezas de plata, o hacerlas acuñar por un correligionario o un no judío en las mellāh $h$-s de Fez (Fās al-Jadid o Fās alBali) por cuenta propia, ya que la acuñación de moneda debía hacerse bajo la responsabilidad de un amin. Se prohibía, así mismo, el envío de plata u oro a otra ciudad para ser empleado en la fabricación de moneda o en el comercio de cambio.

Sin embargo, en el sur de Marruecos, la situación de las comunidades judías distó bastante de la que se dio en la capital idrīsí. Muchas tribus judías estaban instaladas en el sur de Marruecos, especialmente en las regiones mineras de Sous y el Draa, en el Medio y Alto Atlas ${ }^{31}$. Como parece demostrado, no fueron solamente factores religiosos los que jugaron un papel fundamental en la expansión idrīsí en el Magreb: el deseo y/o la necesidad de controlar las minas de plata de la región sería decisivo en la conquista del territorio y el sometimiento a su autoridad de las tribus locales cristianas y judías ${ }^{32}$.

${ }^{29}$ Como en toda analogía, hay que ser cautos a la hora de extrapolar los datos. No obstante, considero que el interés del texto justifica su inclusión en este trabajo. Otras fuentes hacen referencia también al activo papel desempeñado por los judíos en la fabricación de moneda, aunque sin aportar nombres propios, para otros períodos más cercanos en el tiempo al período idrīsí, como es el caso del período meriní o benimerí, cuya información será analizada en un próximo trabajo en curso de realización.

${ }^{30}$ ZAFRANI, Haïm, Deux mille ans..., 152. Zafrani aporta la noticia de éste y los siguientes textos pero no ofrece indicación alguna sobre su origen o localización.

${ }^{31}$ SCHROETER, Daniel, TSUR, Yaron, HATIMI, Mohammed, "Morocco"...; SCHROETER, Daniel, "Berber Jews" en Encyclopedia of Jews in the Islamic World. [En línea] Executive Editor Norman A. Stillman. Brill Online, 2015. Disponible en:

http://ezproxy.library.nyu.edu:2358/entries/encyclopedia-of-jews-in-the-islamic-world/berber-jewsSIM_0004140 [Último acceso 05 de enero de 2015]

${ }^{32}$ ROSENBERGER, Bernard, "Autour d'une grande mine d'argent du Moyen Âge marocain: Jebel Aouam" en Hespéris-Tamuda, V (1964), 15-78, 72; MANZANO MORENO, Eduardo, "El desarrollo económico de las ciudades idrīsíes: la evidencia numismática" en P. Cressier, M. García - Arenal (eds.), Genèse de la ville islamique en al-Andalus et au Maghreb occidental, Casa de VelázquezCSIC, Madrid, 1998, 353-375, 354; GARCÍA-ARENAL, Mercedes, MANZANO MORENO, Eduardo, "Légitimité et villes idrissides" en P. Cressier, M. García - Arenal (eds.), Genèse de la ville islamique en al-Andalus et au Maghreb occidental, Casa de Velázquez-CSIC, Madrid, 1998, 257-284. 


\section{LOS JUDÍOS Y LA EXPLOTACIÓN MINERA EN MARRUECOS DURANTE EL PERÍODO IDRĪSÍ}

Según las fuentes árabes, fue el mismo Idrīs I quien incorporó la región de Fāzāz a los territorios idrīsíes ${ }^{33}$, región que estaba habitada por tribus judías y donde las tradiciones atribuyen la explotación de las minas de plata por dichas tribus desde antes de la llegada del islam. Y es en esta región donde se encuentran las minas conocidas del noroeste del Medio Atlas: La Qal'a, 'Awwām y Warkinnās, junto a la misma Fāzāż3.

Qal'a es la capital de Fāzāz. Conocida también como Madīnat Fāzāz, fue fundada por Mahdī Ibn Tawālā el-Yežfešî, hijo y sucesor del primer emir de Fāzāz. Situada entre Umm Rabī‘ y Fās, estaba habitada por Zanātas y sus comerciantes eran mayoritariamente judíos. Próxima a la ciudad se encontraba la mina de plata (Qal'at Mahdī) ${ }^{35}$.

En cuanto a la mina de 'Awwām, Eustache consideró, con las debidas reservas, que el topónimo podría estar en relación con la tribu 'Avvīm, mencionada en el Antiguo Testamento (Deuteronomio II, 23 ${ }^{36}$; Josué XIII, $3^{37}$ ), que habitaba en los alrededores de Gaza, y que fue exterminada por invasores llegados de Creta. Propuso que, debido a la alternancia vocálica bereber a/i, podría tratarse del origen del topónimo: 'Awwīm/'Awwām. Sin embargo, no está claro que los Heveos fueran realmente una tribu judía ni que no se trate de la misma tribu de los Horeos ${ }^{38}$, si bien es cierto que el término "horeo" puede significar morador de cuevas"

${ }^{33}$ IBN ABĪ ZAR', al-Anīs al-Muṭib bi-Rawḍ al-Qirțas fì Ajbār Mulūk al-Magrib wa Tārīj Madīnat Fās, Rabat, Dār al-Manșūr li-1-Tibā’a wa 1-Wirāqa, 1972, I, 40; IBN JALDŪN, Histoire des Berbères et des dynasties musulmanes de l'Afrique septentrionales, Trad., Le Baron de Slane, París, 1925, 4 vols., I, 209.

${ }^{34}$ Sobre la minería en el Magreb occidental y en especial sobre las minas de plata en la región, durante la Edad Media, otras referencias fundamentales son: GSELL, Stéphane, "Les vieilles exploitations minières dans l'Afrique du Nord", Hespéris, VIII (1928), 1-21; EUSTACHE, Daniel, "Les ateliers monétaires du Maroc", Hespéris-Tamuda, XI (1970), 95-102; ROSENBERGER, Bernard, "Les vieilles exploitations minières et les centres métallurgiques du Maroc, essai de carte historique (1 ${ }^{\text {ère }}$ partie)", Revue de Géographie du Maroc, 17 (1970), 71-108; ROSENBERGER, Bernard, "Les anciennes exploitations minières et les anciens centres métallurgiques du Maroc (2 $2^{\text {ème }}$ partie)", Revue de Géographie du Maroc, 18 (1970), 59-102; ROSENBERGER, Bernard, "Tamdult, cité minière et caravanière présaharienne. $\mathrm{IX}^{\mathrm{e}}-\mathrm{XIV}^{\mathrm{e}}$ siècles", Hespéris-Tamuda, XI (1970), 103-139; BEN ROMDHANE, Khaled, "Exploitation des métaux précieux au Magheb médiéval" en A. Canto, P. Cressier (eds.), Minas y metalurgia en al-Andalus y Magreb Occidental. Explotación y poblamiento, Casa de Velázquez, Madrid, 2008, 1-18.

${ }^{35}$ EUSTACHE, Daniel, Corpus des dirhams Idrīsites..., 92.

36 "Los heveos, que habitaron los cortijos hasta Gaza, fueron destruidos por los caftorim, que salidos de Caftor, se estableciron en su lugar".

37 “...desde el Sijor, que corre al oriente de Egipto, hasta la frontera de Acarón, hacia el norte, que se reputa como de los cananeos; los cinco príncipes de los filisteos, el de Gaza, el de Azoto, el de Ascalón, el de Gat, el de Acarón; los jeveos al mediodía...".

${ }^{38} \mathrm{http}: / /$ www.wikicristiano.org/diccionario-biblico/2315/heveos/ [Último acceso el 17 de diciembre de 2014].

${ }^{39} \mathrm{http} / / /$ wol.jw.org/es/wol/d/r4/lp-s/1200002041 [Último acceso el 17 de diciembre de 2014]. 
Más seguro parece el origen del nombre de la mina de plata de Warkinnās. Próxima a la Qal'at Mahdī, a tres etapas $(120 \mathrm{~km})$ de Miknās (Mequinez), toma el nombre de un personaje legendario del sur de Marruecos: el santo judío Wārkennās, que cuenta con un santuario en el anti Atlas, en pleno territorio minero. El topónimo viajaría al norte de la mano de los judíos del anti Atlas ${ }^{40}$. La leyenda de la llegada de este personaje al actual Marruecos fue recogida por $\mathrm{Colin}^{41}$ : tres profetas perseguidos por Nabucodonosor llegaron al través del mar a las costas de Māssa, desde donde se dirigieron al interior de Sūs. Uno de ellos, Dānīyāl (Daniel) está enterrado en Tagmūt (al noroeste de Tata); otro, Šanāwel (Samuel) lo está en Tamdult (TamdoultAqqa); y el tercero, Walkennās (o Warkennās) es todavía recordado por las gentes del Souk Izkīl (Ezequiel), situado al pie de una montaña entre Tazagt (Tizeght) y el oued des Isäffen (territorio de los Illalen). La leyenda recoge así la memoria colectiva de la explotación de las minas de plata en la región por la población judía desde antes de la llegada del islam ${ }^{42}$.

Las comunidades judías no solamente trabajaron en la explotación de las minas, sino que acuñaron moneda en cecas asociadas a estas zonas mineras que controlaron, dejando su huella en el numerario, a través de una serie de signos y símbolos, como vamos a ver a continuación.

\section{SIGNOS Y SÍMBOLOS HEBREOS EN LA MONEDA IDRĪSÍ Y DE SUS CONTEMPORÁNEOS}

Resulta muy interesante comprobar que no será en las monedas salidas de la ceca de Fez, a pesar de la importancia de la comunidad judía y de su dedicación a la acuñación, en las que encontraremos signos y caracteres hebreos sino, fundamentalmente, en las de las cecas de Mrīra, Tudga e İ $k_{a m}^{43}$. Sin embargo, hay una serie de símbolos, con bastante probabilidad de carácter judáico, que sí estarán relacionados con la

${ }^{40}$ EUSTACHE, Daniel, Corpus des dirhams Idrīsites ..., 93-94.

${ }^{41}$ COLIN, Georges S., "Les mines marocaines" en Bulletin économique du Maroc, III/13 (1936), 197. Es citado por Eustache, nota 52, pág. 101, quien remite también a VOINOT, Louis, Pèlerinages judéo-musulmans du Maroc, Institut des Hautes-études Marocaines, Larose, Paris, 1948, 83.

${ }^{42}$ Recogida por Eustache (EUSTACHE, Daniel, Corpus des dirhams Idrīsites..., 101, nota 48). La importancia de la leyenda es destacada también por García Arenal y Manzano (GARCÍA-ARENAL, Mercedes, MANZANO MORENO, Eduardo, "Légitimité et villes idrissides"...).

${ }^{43}$ Los ejemplares conocidos con dichos signos y caracteres hebreos son muy escasos y en ocasiones se trata de ejemplares únicos, como podrá comprobarse a lo largo del texto, frente al total de ejemplares recogidos en el Corpus de Eustache que supera los 450 para la moneda idrīsí. Tipológicamente hablando su representación también es escasa. No obstante, ello no le resta importancia en relación al tipo de análisis que se presenta en este trabajo. En primer lugar, porque el número de ejemplares en circulación fue, obviamente, mucho mayor; en segundo lugar, porque en una disciplina como la numismática islámica, son muchos los casos en los que es un único ejemplar el que viene a documentar los hechos históricos relatados por las fuentes o incluso a aportar nuevos datos no recogidos en las fuentes literarias. 
capital idrīsí, a través de su ceca al-'Alīya (orilla izquierda de Fez), y con otras cecas como Walīla, Wațīt y Wazeqqūr, como se verá a continuación. Esta constatación numismática vendría a refrendar la idea de que los judíos del sur de Marruecos llegaron a constituir poderes semiindependientes. Sin embargo, éstos debieron ser únicamente de carácter tribal y muy local, ya que no parece que pueda constatarse desde el punto de vista numismático la afirmación de que llegaron a constituir "una especie de Estado judio independiente", como se ha llegado a afirmar ${ }^{44}$, ya que no parece haber ningún elemento de peso que vincule las emisiones de unas cecas con las de otras, como podrá comprobarse.

\subsection{LETRAS AISLADAS}

Podemos encontrar una serie de letras hebreas en algunos ejemplares de dirhames

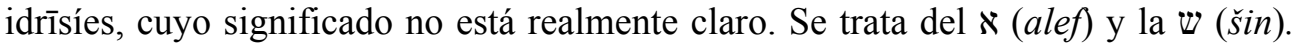
Ya Eustache planteó tres posibilidades al respecto. La primera, que se tratara de la abreviatura de un nombre judío. La segunda, que fuera la primera letra de una palabra hebrea. La tercera, que tal vez tuviera un valor numérico, apuntando los numerales 1 y 400 respectivamente ${ }^{45}$. Partiendo de estas propuestas interpretativas de Eustache, habría que intentar saber a qué nombres o términos podrían estar haciendo referencia. Aunque es prácticamente imposible tener una certeza al respecto, si pueden hacerse una serie de propuestas de una razonable verosimilitud.

El alef aparece en las emisiones idrīsíes del año 201/816-817, atribuidas a Idrīs II, de la ceca de Mrìra (Eustache Idr. 262). La ceca Mrīra, estaba situada en las proximidades del actual Mrīrt, próximo a Kenifra, en el noroeste del Medio Atlas, en la antigua región de Fāzāz, y próxima a la mina de plata de Jbel Aouam (Jbel 'Awwām). Región y minas, como hemos visto, asociadas a la población judía magrebí más antigua. Inició su actividad durante el gobierno de Idrīs II, permaneciendo activa entre el año 200/815-816 y el 204/819-82046, por lo que los ejemplares en los que figura el alef datan del inicio de su actividad. Éste se sitúa a la izquierda del nombre Idrīs que figura sobre la leyenda central del reverso (II.A. ${ }^{47}$.

\begin{tabular}{|c|c|c|c|}
\hline I.A. & & II.A. & \\
\hline & & ادريس א & alef Idrīs \\
\hline محمد & No hay dios sino & Muhammad \\
\hline
\end{tabular}

${ }^{44}$ Cf. BENSABAT, Salomón J., "Los judíos en Marruecos”..., 20.

${ }^{45}$ EUSTACHE, Daniel, Corpus des dirhams Idrīsites..., 84. En el caso del valor numérico de la šin debe tratarse de un error pues a la letra le corresponde el valor numeral de 300 (Cf. entre otros CIRLOT, Juan Eduardo, Diccionario de símbolos, Ed. Labor, Barcelona, (6 ${ }^{\mathrm{a}}$ ed.) 1985, 275).

${ }^{46}$ EUSTACHE, Daniel, Corpus des dirhams Idrīsites..., 151-152.

${ }^{47}$ Así se indica en EUSTACHE, Daniel, Corpus des dirhams Idrīsites..., 356 (véase la lám. XIV). Sin embargo, en el catálogo no figura indicado el alef (cf. pág. 236), por lo que debe tratarse de una errata. 


\begin{tabular}{|c|c|c|c|}
\hline الله وحده & Dios, Único & رسول & Mensajero \\
\hline لا شريك له & No tiene compañero & 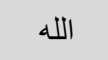 & de Dios \\
\hline على & 'Alī & بخ على * & excelente $^{* *}$ Ali \\
\hline
\end{tabular}

\begin{tabular}{|c|c|c|}
\hline I.M. & ... بمريرة سنة احدى و مئتين & ...en Mrīra año doscientos uno \\
\hline II.M. & محمد رسول الله أرسله بالهدى الخ & $\begin{array}{c}\text { Muhammad es el Mensajero de Dios, le en- } \\
\text { vió con la orientación... }\end{array}$ \\
\hline
\end{tabular}

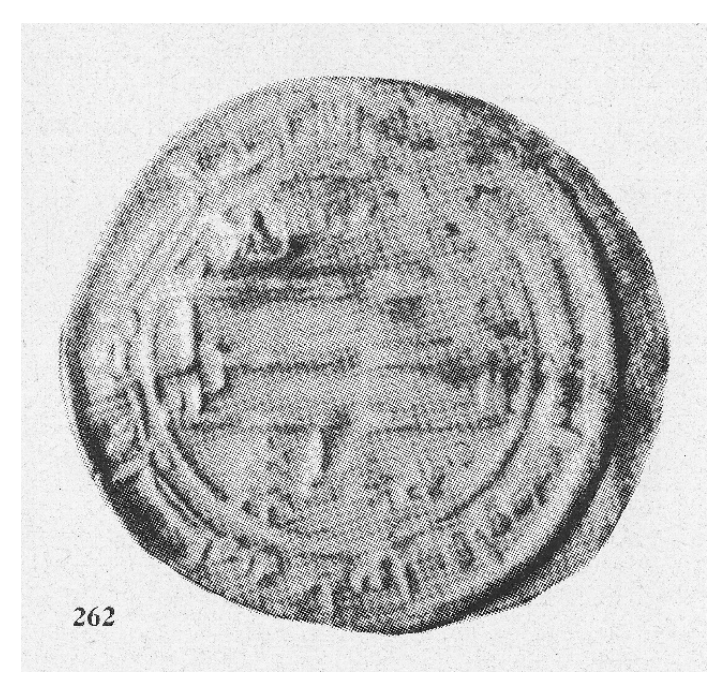

Imagen 1: II.A. Eustache Idr. 262, Lám. XIV

$\mathrm{Al}$ alef, como primera letra del alfabeto hebreo, se le atribuye el valor numérico de 1. Así mismo, el uno hace referencia a la Unicidad, uno de los atributos de Dios, y representa la presencia Divina. Simboliza la espiritualidad, el principio y el fin de la vida $^{48}$. Aunque no creo que pueda atribuírsele en este momento una interpretación cabalística a la letra, por lo que no voy a entrar en su análisis en este sentido, es in-

* Palmera de siete brazos.

** El término بخ "bueno, excelente" hace referencia al peso de la moneda.

${ }^{48}$ CHEVALIER, Jean, GHEERBRANT, Alain, Diccionario de los simbolos, Ed. Herder, Barcelona, $6^{\circ}$ Ed. 1999, 639-642. 
teresante tener presente que se le atribuye el significado de "toro" y de "dueño" Pero sobre todo, el $\mathrm{N}$ es la inicial del término para designar a Dios: Elohim.

Otra posibilidad es que se tratara de la inicial de un nombre propio. En ese caso, la onomástica judía documentada en Marruecos ofrece varias posibilidades. Corcos recogió treinta y tres nombres propios que comenzaban por $\aleph^{50}$. De ellos hay uno especialmente interesante: se trata del nombre אביעזד (Abi'ezer). Fischer ${ }^{51}$ lo atribuyó al comandante de un ejército judío llamado Benyamin ben Jehoushfăt ben Abi ‘ēzer, que luchó como aliado de Idrīs I para posteriormente enfrentarse a él. De su figura se hicieron eco autores posteriores como Slouschz y Toledano ${ }^{52}$. Sin embrago, Corcos, aun aceptando la existencia de dicho nombre en Marruecos, consideró que tal personaje era fruto exclusivo de la imaginación de Fischer ${ }^{53}$. De haber realmente existido un líder judío de tal nombre que se enfrentará a la expansión Idrīsí, atribuirle la autoría de la moneda entra en el terreno de la pura especulación. Sin embargo, resulta interesante la misma posibilidad en sí, pues bien pudo responder el $\mathrm{N}$ a la inicial del nombre del líder tribal que acuñara la moneda.

En esta misma línea, también resulta especialmente interesante el nombre אידיר, ya que no sólo se trata de un nombre bereber documentado ya por las fuentes árabes en el siglo IV/X, sino que es el nombre del líder de una tribu Zanata, los Toujīn: Yedder Ibn Loqman ${ }^{54}$.

De tratarse realmente de la inicial de un nombre propio estaríamos ante un signo de carácter político que debió identificar bien a un dirigente tribal bien a la tribu en sí. En este caso, debieron reconocer el poder político idrīsí acuñando moneda a su nombre, y probablemente pagándole los derechos de la acuñación, como solía hacerse, pero dejando patente su identidad judía.

En último caso, hay que apuntar la posibilidad de que se tratara sencillamente del signo del artesano judío que abriera el cuño monetal. Salvando las distancias, está documentado el uso del $\boldsymbol{N}$ en las emisiones de monederos judíos en la Europa cristiana del siglo XIII, como es el caso de las llevadas a cabo por el monedero Altman ben Chenok durante el breve reinado de Esteban V de Hungría (1270-1272) ${ }^{55}$. Si bien es cierta la diferente situación de los judíos en la Europa cristiana donde sí

\footnotetext{
${ }^{49}$ PERADEJORDI, Julio, La Cábala, Ed. Obelisco, Barcelona, 1996, 2a ed. 2004, 74, 85-86.

${ }^{50}$ CORCOS, David, Studies in the History of the Jews of Morocco, Rubin Mass, Jerusalén, 1976, 198-202.

${ }^{51}$ FISCHER, Meyer, Toldoth Yeshouroun, Praga, 1817.

${ }^{52}$ SLOUSCHZ, Nahum, Etude sur l'Histoire des Juifs et du Judaïsme au Maroc, París, 1906; TOLEDANO, Jacob Moses, Neer ha-Ma 'arav, Jerusalén, 1911. Citados por CORCOS, David, Studies in the History..., 199.

${ }^{53}$ CORCOS, David, Studies in the History..., 199.

${ }^{54}$ CORCOS, David, Studies in the History..., 200.

${ }^{55}$ Huszár 357 (HUSZÁR, Lajos, Munzkatalog Ungarn, Ed. alemana: Munzkatalog Ungarn: Von 1000 bis Heute, Battenberg 1979), Unger 268 (UNGER, Emil, Magyar éremhatározó, Budapest, 1997), Réthy I 298v (RÉTHY, Lászlo, Egyetemes Magyar Éremtár, vols. I-II, Budapest, 18991907, reed. Budapest, 1982).
} 
podían recibir, y recibían, licencias de acuñación ${ }^{56}$, y salvando las distancias, el hecho en sí del uso del alef merece especial atención.

Tanto si se tratara de un símbolo de carácter religioso ( $\aleph$ como inicial de Elohim) como simplemente monetal, o de carácter político, como considero más probable, identificaría al acuñador de la moneda y su condición de judío.

En cuanto a la letra $\boldsymbol{w}(\sin )$, la encontramos en emisiones atribuidas también a Idrīs II, de la ceca de İkam, del año 204/819-820 (Eustache Idr. 423) ${ }^{57}$ :

\begin{tabular}{|c|c|c|c|}
\hline I.A. & & II.A. & \\
\hline & & ادريس & Idrīs \\
\hline لا اله الا & No hay dios sino & محمد & Muhammad \\
\hline الله وحده & Dios, Único & رسول & Mensajero \\
\hline على & $' A l \bar{l}$ & الله - الله & de Dios \\
\hline لا شريك له & No tiene compañero & على & 'Alī \\
\hline$w^{* *}$ & šin & & \\
\hline
\end{tabular}

\begin{tabular}{|c|c|c|}
\hline I.M. & ... بيكم سنة اربع و منتتين & ...en Īkam año doscientos cuatro \\
\hline II.M. & محمد رسول الله أرسله بالهدى الخ & $\begin{array}{c}\text { Muhammad es el Mensajero de Dios, le envió con } \\
\text { la orientación... }\end{array}$ \\
\hline
\end{tabular}

${ }^{56}$ Tenemos en España sin ir más lejos el caso, por ejemplo, de los mancusos realizados por los monederos judíos Bonom y Eneas (BALAGUER, Anna Ma , Del Mancús a la Dobla. Or y paries d'Hispània, Asociación Numismática Española, Societat Catalana d'Estudis Numismàtics, Barcelona, 1993, 23-69, 136-149; ARIZA ARMADA, Almudena, De Barcelona a Orán. Las emisiones monetales a nombre de los califas hammūdies de al-Andalus, Editorial OMNI, Grenoble, 2015, 339-349, 436437, 571-574. Un estudio comparativo entre la situación de los monederos judíos en los reinos cristianos y en los territorios islámicos es otro de los muchos temas relacionados con lo aquí tratado que merece un estudio en profundidad.

${ }^{57}$ EUSTACHE, Daniel, Corpus des dirhams Idrīsites..., 269.

* Figura una palmera a la derecha de 'Alī y un círculo a la izquierda.

** Figura una estrella al lado izquierdo de la šin. 


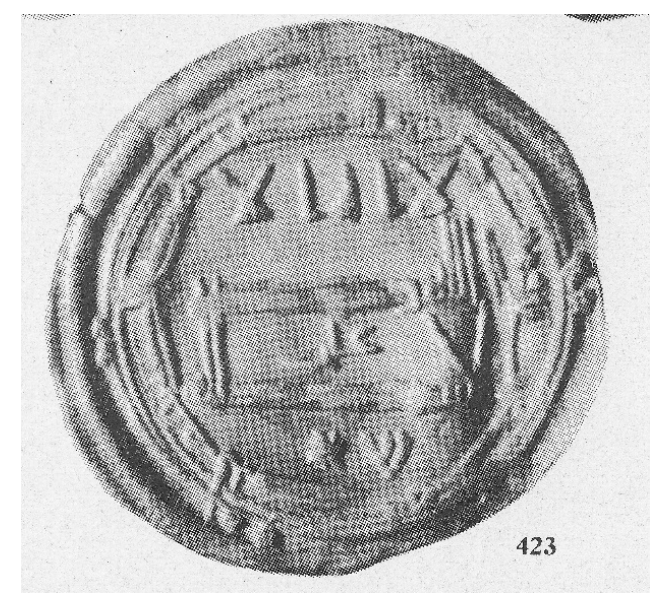

Imagen 2.: I.A. Eustache Idr. 423, Lám. XXV

Se trata del único ejemplar idrīsí que recoge Eustache de la ceca de $\bar{I} k a m$, ceca que se encontraría en una localidad ya desaparecida a orillas del río del mismo nombre $(\text { Oued Yquem) })^{58}$.

En cuanto a la $\boldsymbol{E}(\check{s} i n)$, como en el caso anterior, puede ser objeto de varias hipótesis interpretativas. Puede tratarse tanto de un signo de carácter religioso, como de legitimación política.

La šin representa el número 300. Es una letra importante ya que con ella empiezan dos de las cualidades atribuidas a Dios: $\check{S}$ alom (paz) y $\check{S}$ adday (Omnipotente, Todopoderoso). Šadday es en sí una de las maneras de nombrar a Dios. Así, si se tratara de un símbolo de carácter religioso, podría ser una referencia a la Divinidad. Además, el término Šadday tiene un fuerte valor santificador y protector, por lo que se graba en las cápsulas y protectores de la mezuzáa ${ }^{59}$. También es la inicial del término Šekina, que hace referencia a la presencia sin límites de Dios junto a los hombres ${ }^{60}$.

La $\boldsymbol{E}$ también está relacionada con importantes eventos de la vida religiosa de la comunidad: es la inicial de šabbat (día de descanso), de šabu'ot (fiesta de las Semanas o de las Primicias, Pentecostés) ${ }^{61}$, de šemini (Octavo) ${ }^{62}$ o de la misma profesión de fe judía (̌̌ema Israel).

Pero también puede ser la inicial de la palabra šeliaj, haciendo referencia al término šeliaj tsibbur, delegado o emisario de la comunidad. O bien de šetar, acta,

\footnotetext{
${ }^{58}$ EUSTACHE, Daniel, Corpus des dirhams Idrīsites..., 173.

${ }^{59}$ DE VRIES, Simon Ph., Ritos y símbolos judios, Caparrós ed., Madrid, 2000, 41-43; GOLDENBERG, André, L'Art chez les Juifs..., 2014, 68-69.

${ }^{60}$ RODRIGUEZ CARMONA, Antonio, La religión judía. Historia y teología, BAC, Madrid, 2001, 339-342.

${ }^{61}$ Como veremos, las alusiones simbólicas a esta fecha fueron frecuentes en la moneda hebrea.

${ }^{62}$ Recuérdese que el Octavo es uno de los símbolos de la Alianza ¿Podría hacer referencia a la Alianza?
} 
contrato $^{63}$. En ambos casos tendría un valor de carácter político, siendo el signo del representante tribal o bien la referencia al acuerdo político entre la tribu e Idrīs II al que estaría sujeta la emisión.

En cuanto a los nombres propios de los que podría ser inicial, Corcos recoge veintitrés nombres judeo marroquíes que empiezan por $\boldsymbol{w}(\breve{s i n})$, de los que no hay ninguno específicamente documentado para este periodo, por lo que, de tratarse de la inicial de un nombre, podría serlo de cualquiera de ellos ${ }^{64}$.

\subsection{NOMBRES PROPIOS}

Frente a los relativamente numerosos nombres conocidos de los responsables de las acuñaciones magrebíes de esta época ${ }^{65}$, solamente conocemos el nombre del que se supone es un grabador judío: Ya'aqob. Su nombre figura en las monedas con caracteres hebreos cuadrados con trazas de arcaísmo. Sobre él, Eustache solamente indicó: "Graveur juif du matriarcat de Zaynab ca. 200H. à Tudga. Le nom est donné en hébreu carré avec traces d'archaïsme. La ligne d'écriture est renversée" ${ }_{60}$.

La aparición de un nombre hebreo en emisiones de la ceca de Tudga (تدغة), no sólo es el testimonio numismático de la presencia de las comunidades judías en la región, cuyo origen parece estar relacionado con las minas próximas de Jebel Saghro, sino que el hecho de que un judío "firme" la moneda, pone de relieve la importancia en esta época de una comunidad que se mantendrá hasta los años 60 del siglo XX en tres aldeas de la región (Tinghir, Taourirt, y Asfalou) ${ }^{67}$.

La ceca Tudga probablemente se encontraba en la desaparecida ciudad del mismo nombre en un oasis al sur del actual Marruecos, al oeste de Tafilalt. Su misma existencia y su gran actividad, de la que tenemos las primeras noticias por las emisiones de dirhames 'abbasíes del año 163/779-780, se han explicado por la existencia de minas de plata en la región. La fundación de Siŷilmāsa (140/757-758), a dos jornadas de Tudga y su rápido crecimiento, habría provocado un progresivo despoblamiento de la ciudad. Despoblamiento que sería definitivo tras la conquista almorávide, con la importancia que adquirió Siŷilmāsa bajo su poder ${ }^{68}$.

${ }^{63}$ DE VRIES, Simon Ph., Ritos y símbolos..., 317.

${ }^{64}$ CORCOS, David, Studies in the History..., 225-229.

${ }^{65}$ Eustache les denomina "Graveur ou monétaire" entendiendo como "monetaire" bien el oficial de la moneda o el ministro de finanzas (EUSTACHE, Daniel, Corpus des dirhams Idrīsites..., 75), sin embargo, como hemos visto, dado que se trata de nombres musulmanes, considero más lógico pensar que se refiera a los responsables monetales.

${ }^{66}$ EUSTACHE, Daniel, Corpus des dirhams Idrīsites..., 75.

${ }^{67}$ BOUM, Aomar, "Todgha" en Encyclopedia of Jews in the Islamic World. [En línea] Executive Editor Norman A. Stillman. Brill Online, 2014. Disponible en: http://referenceworks.brillonline.com/entries/encyclopedia-of-jews-in-the-islamic-world/todghaSIM_0021330 [Último acceso el 05 de diciembre de 2014].

${ }^{\overline{6}}$ EUSTACHE, Daniel, Corpus des dirhams Idrīsites..., 131 y 135, nota 4. 
Los ejemplares conservados indican que la ceca de Tudga acuñó moneda a nombre de Idrīs I y al de Idrīs II hasta el 187/802-803, para reiniciar la acuñación en el 220/835 ya a nombre de Yahyà b. Idrīs II. Eustache consideró que el papel de los comerciantes y banqueros judíos en el comienzo de las acuñaciones idrīsíes de la ceca no debió ser menor: Idrīs I habría obtenido la autorización del imām de Tudga, territorio que no se encontraba por entonces bajo su dominio, en gran medida gracias a la intervención de los comerciantes y banqueros judíos. Según Eustache, el hecho de que estuviera gobernado por los jāriŷíes, no debió ser un obstáculo para que los dos primeros idrīsíes llegaran a algún tipo de acuerdo con ellos, a pesar de que fueran sus principales rivales. Probablemente las tendencias mu'tazilíes que atribuyen las fuentes árabes al primer idrīsí, pudieron facilitar el acuerdo. Así, mientras acuñaba moneda a nombre de los idrīsíes, la ceca de Tudga continuó batiendo dirhames a nombre de los emires jāriŷ́ies del momento (Jalaf b. al-Maḍā' y 'Amr b. Hammād) ${ }^{69}$.

El nombre $Y a$ 'aqob figura en, al menos, dos ejemplares de ceca y fecha ilegibles pero atribuidos a esta ceca (Eustache dirh. contemp. 75 y 76). Sus leyendas, según Eustache, son:

\begin{tabular}{|c|c|c|c|}
\hline I.A. & & II.A. & \\
\hline & & $k \pi$ \& & $Y a^{\prime} a q o b$ \\
\hline لا اله الا & No hay dios sino & محمد & Muhammad \\
\hline الله وحده & Dios, Único & رسول & Mensajero \\
\hline لا شريك له & No tiene compañero & الله & de Dios \\
\hline-113 & Zaynab (¿?) & مسع & mu'tabar (ejemplar) \\
\hline
\end{tabular}

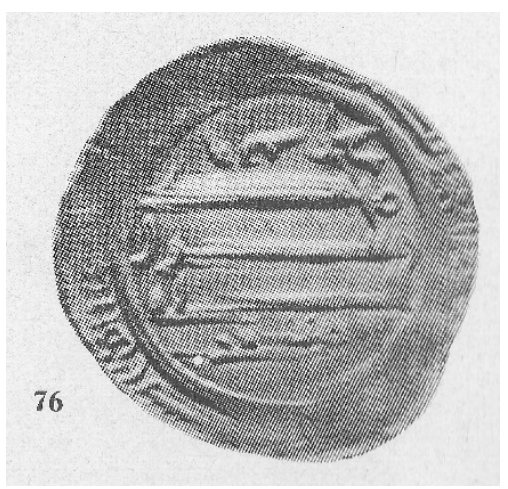

Imagen 3: II. A. Eustache dirh. contemp. 76, Lám. XXXIII

${ }^{69}$ EUSTACHE, Daniel, Corpus des dirhams Idrīsites..., 133-134. 
Como puede verse, Eustache leyó, con ciertas reservas, el nombre que figura bajo la leyenda central de la I.A. como Zaynab. Este nombre aparece también en dirhames fechados el año 200/815-816 (Eustache dirh. contemp. 74), lo que sitúa la data de los ejemplares que nos ocupan hacia dicho año. Eustache planteó la posibilidad de que, si la lectura que proponía fuese correcta, pudiera tratarse del testimonio de la existencia de un matriarcado bereber en este momento en la localidad ${ }^{70}$. Indicaba, así mismo, que los Ait Zīneb son aún conocidos en la actualidad al oeste de Ouarzazate, a donde se habrían dirigido tras la ruina económica de Tudga ${ }^{71}$. Sin duda, la importancia de su hipótesis es enorme. Sin embargo, por salirse del tema que nos ocupa en este momento, relegaré el tema a futuros trabajos. No obstante, aunque no vaya a abordar en el presente estudio la cuestión del matriarcado, no puedo dejar de indicar ahora lo interesante que resulta el hecho de que el único nombre judío que conocemos esté relacionado con un posible matriarcado, siendo conocidos ya otros casos de posibles matriarcados judíos como es el caso de la famosa al-Kahina ${ }^{72}$.

En cuanto al reverso de los ejemplares, Eustache consideró que sobre la leyenda central de la II.A. puede leerse el nombre $Y a{ }^{\prime} a q o b$ en caracteres hebreos arcaicos y, bajo la leyenda, lo que consideró debe tratarse de la fórmula mu 'tabar. Eustache tradujo el término como "ejemplar" indicando que haría referencia a la validez de la moneda ${ }^{73}$. El término también podría traducirse como "considerable" o "considerado", "respetable", y siguiendo la afirmación de Eustache, sería el equivalente a otras fórmulas empleadas por los idrīsíes y sus contemporáneos en la zona, para atestiguar la buena calidad de la moneda: amara bi-l-ḥaqq ("Él ha ordenado la rectitud"), haqq ("rectitud"), tayyib ("buen peso"), 'adl ("peso justo"), o wafr ("abundancia, generosidad de peso"). Sin embargo, si aceptamos esta lectura, supondría que Ya'aqob fue algo más que un simple grabador, pues su nombre estaría certificando la calidad de la moneda. Sería por tanto el responsable de la acuñación, lo que si no sería verosímil bajo un poder islámico, sí podría serlo si realmente estuviéramos delante de un matriarcado judío. No obstante, desde mi punto de vista, la lectura propuesta por Eustache, desde un punto de vista puramente epigráfico, debe revisarse, aunque no me encuentro ahora en condiciones de ofrecer una lectura mejor. En mi opinión, no habría que descartar la posibilidad de que se tratara de un

${ }^{70}$ EUSTACHE, Daniel, Corpus des dirhams Idrīsites..., 134.

${ }^{71}$ EUSTACHE, Daniel, Corpus des dirhams Idrīsites..., 68. Cita el Répert. Alphab. des agglomérations, p. 257. Actualmente Ait Zineb es un enclave rural de la provincia de Ouarzazate en la región de Souss-Massa-Drāa, que contaba en el año 2004 con una población de 9.233 habitantes (Cf. Recensement general de la population et de l'habitat de 2004, [En línea] Haut-Commissariat au Plan, Royaume du Maroc, 2004. Disponible en:

http://www.lavieeco.com/documents_officiels/Recensement\%20population.pdf [Último acceso 05 de diciembre de 2014].

${ }^{72}$ TAÏEB, J., "Juifs du Maghreb : onomastique et langue, une composante berbère?" en 26 | Judaïsme - Kabylie, [En línea] Aixen-Provence, Edisud («Volumes», n 26), 2004. Disponible en: http://encyclopedieberbere.revues.org/1373 [Último acceso el 23 de diciembre de 2014].

${ }^{73}$ EUSTACHE, Daniel, Corpus des dirhams Idrīsites..., 79. 
nombre propio, dado el lugar que ocupa en el campo de la moneda y el hecho de que en uno de los ejemplares en los que figura dicha leyenda no aparezca el nombre hebreo (Eustache dir. contemp. 74).

\subsection{OTROS TÉRMINOS HEBREOS}

También se atribuye a la ceca Tudga la tipología representada por un ejemplar no idrīsí, de ceca y fecha ilegible, cuya acuñación se atribuye a Jalaf b. al-Maḍā' (187190/802-806) (Eustache, dirh. Contemp. 72) ${ }^{74}$. Sus leyendas son:

\begin{tabular}{|c|c|c|c|}
\hline I.A. & & II.A. & \\
\hline & & خلف & Jalaf \\
\hline لا لاله الا & No hay dios sino & محمد & Muhammad \\
\hline الله وحده & Dios, Único & رسول & Mensajero \\
\hline אמת - אי & Verdad & الله & de Dios \\
\hline لا شريك له & No tiene compañero & خلف & Jalaf \\
\hline
\end{tabular}

\begin{tabular}{|c|c|c|}
\hline I.M. & Leyenda circular ilegible. & \\
\hline II.M. & محمد رسول الله أرسله بالهـى الخ & $\begin{array}{c}\text { Muhammad es el Mensajero de Dios, le envió } \\
\text { con la orientación... }\end{array}$ \\
\hline
\end{tabular}

A diferencia del nombre Ya'aqob, אמת ('emet) aparece en caracteres hebreos cuadrados. Eustache tradujo el término como "rectitud", poniendo de relieve que su traducción en árabe es haqq, y por tanto, su función en la moneda sería similar a la de la fórmula árabe amara bi-l-haqq (wa-l-wafä') haciendo referencia a la rectitud del peso de la moneda ${ }^{75}$. Efectivamente, el término hebreo puede hacer referencia a aquello que es firme, digno de confianza, fidedigno, y por tanto aludiría a la legalidad de la pieza. Sin embargo, no hay que pasar por alto el hecho de que esta tipología es muy anterior en el tiempo a las idrīsíes que utilizan la fórmula amara bi-l-haqq, que datan de los años 242/856-857 y $245 / 859-860^{76}$, por lo que difícilmente puede ser una adaptación en hebreo de la fórmula árabe. En todo caso, considero que lo realmente interesante no es tanto el uso del término, que lo es, como el hecho de que aparezca grabado en caracteres hebreos, pues indica la intencionalidad de que fuera leído y comprendido por los bereberes judíos. Podría

\footnotetext{
${ }^{74}$ EUSTACHE, Daniel, Corpus des dirhams Idrīsites..., 302. Sin reproducción gráfica en el Corpus.

${ }^{75}$ EUSTACHE, Daniel, Corpus des dirhams Idrīsites..., 79.

${ }^{76}$ Eustache Idr. 246, 252-254.
} 
estar hablando, por tanto, de una invitación a la comunidad judía a aceptar la moneda islámica en sus intercambios comerciales.

No obstante, esta clara intencionalidad, unido a la antigüedad de la data y al hecho de que en el caso de la emisiones no idrīsíes conocidas, como es el caso de ésta que nos ocupa, en primer lugar, los términos que hacen referencia a la legitimidad de la moneda (tayyib, 'adl, wafr) aparecen siempre en el reverso, y en este caso lo hace en el anverso y en caracteres hebreos y no árabes; y en segundo lugar, que es la única tipología que incluye una leyenda entre la segunda y tercera línea de las leyenda central, permite plantear una nueva lectura del término, esta vez de carácter religioso. אמת no sólo designa aquello que es firme, digno de confianza, estable, sino que sobre todo puede traducirse literalmente por "verdad", y hacer referencia a un hecho veraz o establecido. Por tanto, si tenemos en cuenta dónde se sitúa el término en la moneda podría considerarse un elemento de propaganda religiosa frente a las tribus hebreas: la verdad del mensaje transmitido en la moneda. Es decir, la Verdad es lo manifestado en la profesión de Fe islámica; lo establecido, el Islam. Es más, dado que la tipología se atribuye al imām jāriŷ́i șufrí de Tudga ${ }^{77}$, ¿sería descabellado pensar que pudiera tratarse de propaganda jāriŷ́, de un intento de ganarse a la población judía frente a sus rivales los idrīsíes?

No obstante, el término nos permite otra lectura más. אמת es uno de los atributos que el judaísmo atribuye a la Divinidad: el Dios de la Verdad, el Dios Fidedigno y Veraz, como es determinado en el Salmo 31, 6: "En tus manos encomiendo mi espiritu. Tú me has rescatado, Yahvé, Dios fiel"' ". Valorar como posible esta lectura, como creo, vendría a reafirmar el papel del término como elemento de propaganda religiosa, recordando al potencial lector judío que el Dios mencionado en el texto árabe es el Único Dios, el Dios de la Verdad. Pero también podría tratarse de un acto reivindicativo, una contestación de carácter religioso de la comunidad judía: acuñaría moneda reconociendo el poder político del imām jāriŷí, pero recordando a sus correligionarios judíos dónde se encuentra la Verdad.

Es interesante recordar, como puso de manifiesto el mismo Eustache, que el término hebreo pasó al bereber y actualmente en el dialecto marroquí se emplea la expresión àjīni l-l-ìmìt "dime la verdad"’’.

\subsection{OTROS SÍMBOLOS}

De entre los varios símbolos que aparecen en la moneda idrīsí, círculos, crecientes lunares, hexagramas, pentagramas... ${ }^{80}$ hay dos, íntimamente relacionados entre sí,

${ }^{77}$ EUSTACHE, Daniel, Corpus des dirhams Idrīsites..., 132-134.

${ }^{78}$ Sagrada Biblia. BAC, Madrid, 1975.

${ }^{79}$ EUSTACHE, Daniel, Corpus des dirhams Idrīsites..., 79.

${ }^{80}$ El hexagrama, para los judíos estrella de David y para los musulmanes sello de Salomón, no fue un símbolo monetal hebreo. Cf. ARIZA ARMADA, Almudena, "Iconografía y legitimación en el califato hammūdí. El símbolo del hexagrama” en Numisma, 254 (2010), 61-83; HENDIN, David, Gui- 
especialmente susceptibles de ser símbolos monetales hebreos: la palma y la palmera. Es cierto que podría tratarse sencillamente de símbolos tribales bereberes, que hagan referencia a los palmerales de la zona, aunque nunca con un carácter animista, pues se encuentran relacionadas con las letras o términos hebreos. También es cierto que la palmera era ya el símbolo más usual en la numismática del norte de África, siendo característico, por ejemplo, de las acuñaciones vándalas y bizantinas de la ceca de Cartago, como reminiscencia de las emisiones púnicas, y que estos ejemplares circularon por el Mediterráneo, llegando incluso a aparecer en excavaciones arqueológicas de la misma ciudad de Jerusalén ${ }^{81}$.

Sin embargo, considero que el hecho de se trate de un símbolo fundamental en la moneda hebrea antigua, el hecho de que aparezca asociado a las letras, nombres y términos hebreos que aparecen en la moneda idrīsí y contemporánea, y el hecho que figure en ejemplares de las cecas de al- 'Alīya (orilla izquierda de Fez), Walīla (Volubilis), Wațit y Wazeqqūr situadas en emplazamientos de importante y numerosa población judía ${ }^{82}$, obliga a plantearse su análisis desde la perspectiva de su posible carácter judaico.

Cirlot indicaba en su diccionario de símbolos que "según los persas, la palmera simboliza la tierra celeste. Aparece en las monedas de Cartago. También en la iconografia mozárabe y románica alusiva a temas biblicos" $"$. Según otros autores, para los Babilonios era un árbol divino y para los egipcios el árbol de la vida; los griegos lo consideraban el árbol de la luz y la consagraban a Helios y Apolo ${ }^{84}$. Fue bajo una palmera que la profetisa Débora juzgó a Israel ${ }^{85}$. Sin embargo, en la iconografía monetal judía este símbolo tiene otro valor muy diferente.

de to biblical coins, Ed. Amphora, Nueva York, 2010. Véase también sobre el símbolo FERNÁNDEZ MEDINA, Esther, "The Seal of Solomon: from magical item to messianic device", en Ilona Regulski et alii., Orientalia Lovaniensia Analecta. Seals and Sealings Practices in the Near East. Developments in Administration and Magic from Prehistory to the Islamic Period, Proceedings of an International Workshop at the Netherlands-Flemish Institute in Cairo, on December 2-3, 2009, UItgeverij Peeters, Lovaina, 2012, 175-187.

${ }^{81}$ BIJOVSKY, Gabriela, "From Carthage to the Holy Land: The "Palm Tree" Nummus" en Israel Numismatic Research, 6 (2011), 163-173.

${ }^{82}$ Ya se ha mencionado la importancia de la comunidad Judía de Fez; de Volubilis (Walīla) proceden nada menos que los primeros restos arqueológicos judíos $\mathrm{y}$, como veremos, es donde la tradición sitúa a la comunidad más antigua llegada en la época del Templo, y era, junto a Fez, un importante centro económico e intelectual de la comunidad judía magrebí (CHETRIT, Joseph, "North Africa, Jews of" en Encyclopedia of Jewish Folklore and Traditions. [En línea] London: Routledge, 2013. Disponible en: http://ezproxy.library.nyu.edu:12622/content/entry/sharpejft/north_africa_jews_of/0 [Último acceso el 13 de enero de 2015]); Wațīt era la ceca de una mina de plata (EUSTACHE, Daniel, Corpus des dirhams Idrīsites..., 160), que como el resto estaría explotada por judíos; y Wazeqqūr se encontraba también en una zona minera (EUSTACHE, Daniel, Corpus des dirhams Idrīsites..., 157).

${ }^{83}$ CIRLOT, Juan Eduardo, Diccionario de símbolos..., 353.

${ }^{84}$ OESTERREICHER-MOLLWO, Marianne, Herder Lexikon Symbole, Herder, Freiburg im Breisgau, 1978 (versión española: MURGA, Purificación, Símbolos, Ed. Rioduero, Madrid, 1983, 171).

${ }^{85}$ BANON, Patrick, Signes et symboles religieux, Flammarion, Paris, 2005, 78. 
La palmera de siete brazos ya había aparecido en la moneda hebrea desde el período asmoneo o macabeo. Lo encontramos en las monedas de los Asmoneos, en las de la dinastía herodiana, en las acuñadas durante el período de los procuradores romanos, en las de las dos guerras judías contra el poder romano y en las conmemorativas de la conquista de Jerusalén por Roma ${ }^{86}$. Así, en la moneda hebrea, la palmera, árbol característico de la zona, se convierte en un símbolo de doble sentido: por un lado, de abundancia y plenitud, directamente asociado a la tierra de los judíos; por otro, será la representación de la antigua Judea. La misma Roma representará a Judea a través de la alegoría de la palmera en la famosa serie "Judaea capta es" ${ }^{\text {" }}$. Tras la derrota de Bar Kojba, Roma sustituyó el nombre de la provincia romana de Judea por la de Siria-Palestina. Así, por extensión, la palmera se trasformaría en el símbolo de Palestina. Esta asociación llegará al punto de que, con el paso del tiempo, hoy la palmera es emblema del moderno estado de Israel ${ }^{88}$. Como en el caso que nos ocupa de la moneda idrīsí, también en la moneda hebrea se representa con siete ${ }^{89} \mathrm{O}$ nueve ramas ${ }^{90}$. La representación con siete ramas se ha considerado que se trata de una alusión simbólica a la menoráa1.

En ocasiones, concretamente en $1 / 2$ shekel de bronce de la primera guerra judía (rebelión de los Zelotes), la palmera se representa con dos cestas a cada lado, lo que se considera una alusión simbólica a la fiesta de las Semanas o de las Primicias (Pentecostés), en la que los judíos estaban llamados a presentar en el Templo de Jerusalén, en señal de gratitud, las primeras cosechas de los siete productos con los que Dios había bendecido la tierra de Israel (miel de dátiles, granadas, uvas, higos, trigo, cebada, y aceite). La relación, por tanto, de este símbolo con el culto a Yahvé y con la peregrinación al Templo de Jerusalén, se ha interpretado como una alusión al Templo cargada de sentimiento de unidad nacional que llevaría a la victoria frente a los enemigos ${ }^{92}$. Un Templo que estuvo profusamente decorado con el motivo de la palmera, encontrándose en sus muros, puertas y pilares ${ }^{93}$.

${ }^{86}$ MADDEN, Frederic William, Coins of the Jews, Georg Olms Verlag, Hildesheim-Nueva York, 1976 (Facsímil de la primera edición de 1881), 73. HENDIN, David, Guide to biblical coins...

${ }^{87}$ MADDEN, Frederic William, Coins of the Jews..., 208 y ss. HENDIN, David, Guide to biblical coins..., 419 y ss.

${ }^{88}$ Cf. HENDIN, David, Guide to biblical coins ..., 351-352.

${ }^{89}$ MADDEN, Frederic William, Coins of the Jews..., 71, 157, 174-175, 198-199, 204, 245. HENDIN, David, Guide to biblical coins..., 254, 324, 329-330, 386-387, 394-395, 401-402.

${ }^{90}$ MADDEN, Frederic William, Coins of the Jews..., 175-176. HENDIN, David, Guide to biblical coins..., 241, 252.

${ }^{91}$ HENDIN, David, Guide to biblical coins..., 351-352. Cf. FINE, Steven, "On the Development of a Symbol: the date Palm Tree in Roman Palestine and the Jews" en Journal for the Study of the Pseudepigrapha, 4 (1989), 105-118.

${ }_{92}$ ROMANOFF, Paul, "Jewish Symbols on Ancient Jewish Coins" en Jewish Quarterly Review 34 (1944) 161-77, 438-40; KADMAN, Leo, The Coins of the Jewish War of 66-73 C.E., Corpus Nummorum Palestinensium vol. III, Schocken, Jerusalén 1960, 90-2; SAMUEL, Claudia W., RYNEARSON, Paul, MESHORER, Ya'akov, The Numismatic Legacy of the Jews as Depicted by a distinguished American Collection, Stack's publications, New York, 2000, 73-75; HENDIN, David, 
En cuanto a la palma, símbolo de vida eterna ${ }^{94}$, cabe indicar que es uno de los tres elementos constitutivos del lulav, ramo formado por una palma (lulav) que le da el nombre, tres ramas de mirto (hadas), dos de sauce (arava), y el etrog (tipo de cítrico). El lulav es un elemento indispensable en la fiesta del Sukkot (de los Tabernáculos o de las Cabañas). Simbólicamente, hoy se considera que el lulav representa al pueblo judío en su diversidad: los practicantes y estudiosos (representados por el etrog), estudiosos y posesores del espíritu de la Torá (por el mirto), los que no practican ni estudian (por el sauce), y la hoja de la palmera representa a los que simplemente creen y practican. El lulav es por tanto símbolo de solidaridad y unidad del pueblo judío ${ }^{95}$. En la época del Templo, había que acudir a él portando el lulav, por lo que, como en el caso de la palmera, se convirtió en una referencia simbólica al Templo de Salomón. Y como tal fue utilizado en las monedas. Como en el caso de la palmera, la hoja de palma figuró en las monedas hebreas de la dinastía Asmonea, de la herodiana, en las de los gobernadores romanos y en las de las dos guerras judías. En las monedas de Bar Kojba, fue asociada a la leyenda "por la redención de Sión" "96, por lo que se le ha atribuido el valor simbólico de identidad nacional y esperanza mesiánica. Incluso se considera la posibilidad de que pudiera contener algún rasgo de asimilación del simbolismo greco-romano de la palma como símbolo de victoria ${ }^{97}$.

A pesar de que la única evidencia epigráfica conservada y constatable ${ }^{98}$, procedente de Volubilis, está fechada en el siglo III algunas tradiciones datan la llegada de los judíos al sur de Marruecos ya en la época del rey profeta Salomón; otras mencionan la existencia de restos arqueológicos que testimoniaban la llegada de hebreos huyendo de las guerras del rey David y su general Yoab; otras mencionan numerosas emigraciones en la época de Nabucodonosor, como hemos visto ${ }^{99}$. Así

Guide to biblical coins..., 351-352, 362; AGUILERA ROMOJARO, M ${ }^{\mathrm{a}}$ Jesús, "El templo de Jerusalén en las monedas hebreas" en El Olivo XXXIV, 72 (2010), 5-29, 24-25.

${ }_{93}$ I Libro de los Reyes 6, 29-35; II Paralipómenos o Crónicas 3:5. Cf. SAMUEL, Claudia W., RYNEARSON, Paul, MESHORER, Ya'akov, The Numismatic Legacy of the Jews as Depicted by a distinguished American Collection, Stack's publications, New York, 2000, 74.

${ }^{94}$ BANON, Patrick, Signes et symboles religieux..., 78.

${ }^{95}$ OUAKNIN, Marc-Alain, Les Symboles du Judaïsme, Editions Assouline, París, 2003, 74.

${ }^{96} \mathrm{Cf}$. HENDIN, David, Guide to biblical coins..., 384 y ss.

${ }^{97}$ MESHORER, Ya'akov, Ancient Jewish Coinage, II, 118; KINDLER, Arie, "Lulav and Etrog as Symbols of Jewish Identity", en R. Deutsch (ed.) Shlomo: Studies in Epigraphy, Iconography, History and Archaeology in Honor of Shlomo Moussaieff, Archaeological Centre Publications, Tel Aviv, 2003, 139- 145, 145; BANON, Patrick, Signes et symboles religieux..., 78-79; AGUILERA ROMOJARO, Ma Jesús, "El Templo de Jerusalén...., 21-24.

${ }^{98}$ Existen referencias orales de la existencia de otras inscripciones, en las que se sustentan algunas de las tradiciones sobre el origen de los judíos en Marruecos (cf. BENSABAT, Salomón J., "Los judíos en Marruecos"..., 17).

${ }^{99}$ COLIN, Georges S., "Les mines marocaines"..., 197; VOINOT, Louis, Pèlerinages judéomusulmans..., 83; EUSTACHE, Daniel, Corpus des dirhams Idrīsites...,93-95 y 101 nota 48; BEN- 
pues, la palma y la palmera difícilmente podrían haber sido traídas como símbolos propios por los primeros exiliados judíos que se instalaron en Marruecos. Sin embargo, ello no implica necesariamente que los símbolos fueran desconocidos por las comunidades judías del Atlas durante el período idrīsí.

En primer lugar, debido a las relaciones existentes entre el Magreb Occidental y Oriente. Estos contactos están testificados por el flujo de moneda idrīsí hacia los territorios orientales del califato, como ponen de manifiesto los hallazgos monetales ${ }^{100}$. Este flujo monetal pone de relieve no solamente la existencia de relaciones comerciales sino también los intercambios de carácter religioso entre ambos territorios. No hay que olvidar que en el período que nos ocupa tanto los sefardíes de la Península Ibérica, como los toshavim del Magreb, dependían de los Gaones de oriente, por lo que los contactos y las consultas debían ser frecuentes ${ }^{101}$. Pero también hay constancia de que, durante la Edad Media, la peregrinación a santuarios sagrados asociados a sucesos milagrosos y/o tumbas de profetas o santos, fue un fenómeno de la religiosidad popular generalizado, a pesar de alejarse de la ortodoxia y haber sido objeto de polémicas religiosas. Son bien conocidas las peregrinaciones y el denominado "culto a los santos" en Marruecos incluso hasta hoy en día ${ }^{102}$, y están también documentadas las realizadas fuera del territorio magrebí. Las fuentes árabes y hebreas indican que, al menos ya desde el siglo V/XI, durante la fiesta de Pentecostés se peregrinaba a la sinagoga de Dammuh (antiguo Menfis, al sur de El Cairo) donde, según la tradición, Moisés había orado y realizado milagros, y tanto desde el Magreb occidental como desde Sefarad, se realizaban peregrinaciones para visitar las tumbas del Profeta Ezequiel y de Esdras en Iraq ${ }^{103}$. $\mathrm{Si}$ bien es cierto que esta información proviene de testimonios posteriores al período idrīsí (al-Maqrizi, documentos del siglo V/XI de la Geniza o Benjamín de Tudela, ya en el siglo VI/XII), es más que probable que este tipo de peregrinaciones se hicieran con anterioridad ${ }^{104}$. Algunas tradiciones incluso llegan a remontar estos

SABAT, Salomón J., "Los judíos en Marruecos"..., 17-18; SCHROETER, Daniel, TSUR, Yaron, HATIMI, Mohammed, "Morocco" ...

${ }^{100} \mathrm{Cf}$. al respecto MANZANO, Eduardo, "El desarrollo económico de las ciudades idrīsíes...", 353-375; HEIDEMANN, Stefan, "The Circulation of North African Dirhams in Northern Mesopotamia - The Dirham Hoard of Tall al-Bī'a/al-Raqqa (t.p.q. 186/802)" en Revue Numismatique, 167 (2011), 451-470.

${ }^{101}$ Será Hasday B. Saprut, ya en el siglo X quien independice Sefarad de los Gaones de Oriente.

${ }^{102}$ VOINOT, Louis, Pèlerinages judéo-musulmans...; BEN-AMI, Issachar, BAREL, Gabriel, Culte des saints et pèlerinages judéo-musulmans au Maroc, Maisonneuve \& Larose,1995; BENAMI, Issachar, Saint Veneration Among the Jews in Morocco, Wayne State University Press, Detroit MI, 1998.

${ }^{103}$ STILLMAN, Norman, “Judaism, History of, Part Iv.b: Medieval Times. Islam”, Encyclopedia of Judaism. [En línea] Leiden: Brill, 2005. Disponible en:

http://ezproxy.library.nyu.edu:12765/content/entry/brilljud/judaism_history_of_part_iv_b_medieval_ti mes_islam/0 [Último acceso el 30 de diciembre de 2014].

${ }^{104}$ Desconozco hasta el momento la existencia de documentación sobre el tema relativa al período Idrīsí, tema que espero abordar en mayor profundidad en trabajos posteriores. 
contactos a la época del rey-profeta Salomón, en cuyos banquetes se servían manjares provenientes de Marruecos ${ }^{105}$.

En segundo lugar, porque la palma y la palmera se habían convertido ya en símbolos iconográficos representados en los feluses omeyas. En la Gran Siria (Bilād $a l-S ̌ a ̄ m){ }^{106}$ la acuñación de feluses se organizó a nivel de los aŷnād (circunscripciones militares) y todo parece indicar que éstos tuvieron una cierta libertad en el diseño de sus tipos, tipos que les distinguirían entre sí107. Así, el ŷund Filisțīn acuñará en las cecas de Ramala y Filasțin (Palestina) feluses cuyo motivo principal era la palmera $^{108}$. En la antigua Judea, se debieron elegir símbolos que identificaran el territorio y que fueran reconocibles como propios y aceptados por la mayoría de la población que lo habitaba ${ }^{109}$. Estos feluses bien pudieron llegar al Magreb con las tropas omeyas y ser conocidos, por tanto, por las poblaciones bereberes. Si bien es cierto, como ya he indicado, que la palmera era un símbolo ya conocido en el norte

${ }^{105}$ BENSABAT, Salomón J., "Los judíos en Marruecos"..., 18.

${ }^{106}$ Es decir, los territorios correspondientes a los límites de la Siria Omeya: la actual Siria, Jordania, Israel, Líbano y algunas zonas de las actuales Iraq y Turquía.

${ }^{107}$ HEIDEMANN, Stefan, "The evolving representation of the early Islamic Empire and its religion on Coin Imagery" en NEUWIRTH, A., SINAI, N., MARX, M. (Eds.), The Qur'ān in Context, Brill, Leiden-Boston, 2010, 149-195, 159, 161. Véase también: WALKER, John, A Catalogue of the Muhammadan Coins in the British Museum, vol. II: A Catalogue of the Arab-Byzantine and PostReform Umaiyad Coins, British Museum, Londres, 1956; BATES, Michael, "History, Geography and Numismatic in the First Century of Islamic Coinage", Schweizerische Numismatische Rundschau 65 (1986), 231-261; BATES, Michael, "The Coinage of Syria Under the Umayyads, 692-750 A.D.", The Fourth International Conference On The History Of Bilād al-Shām During the Umayyad Period: Proceedings of the Third Symposium, 2-7 Rabī' I 1408 A.H./24-29 October 1987, English Section, Vol. II ed. M. Adnan Bakhit and Robert Schick (Amman, 1989), 195-228; Arabic translation by Nā'if alQasūs, "Maskūkāt Sūriyya fĩ fitrat al-khilāfa al-umawiyya, 73 [sic]-132 h. (692-750 m.)", Yarmouk Numismatics 2, no. 1 (1990), 15-51; ILISCH, Lutz, Sylloge Numorum Arabicorum Tübingen, Palästina, IVa , Bilād aš-Šàm I. Tübingen, 1993; TREADWELL, W. L., The Chronology of the Pre-Reform Copper Coinage of Early Islamic Syria. Londres, 2000; ALBUM, Stephen, GOODWIN, Tony, Sylloge of Islamic Coins in the Ashmolean, vol. I: The Pre-Reform Coinage of the Early Islamic Period, Oxford, 2002.

${ }^{108}$ ARIZA ARMADA, Almudena, "Aniconismo e iconografía monetal en al-Andalus" en A. Janzon (Ed.), Primer Simposio España y Estados Unidos. Una mirada desde el Instituto Internacional, Madrid, 2001, 23-33, 29. Cf. WALKER, John, A Catalogue of the Muhammadan Coins in the British Museum, vol. II: A Catalogue of the Arab-Byzantine and Post-Reform Umaiyad Coins, British Museum, Londres, 1956, $\mathrm{n}^{\circ}$ 593; MITCHINER, Michael, Oriental Coins and their values, vol. I: The World of Islam, Hawkins Publications, Londres 1977, $\mathrm{n}^{\circ} 87$.

${ }^{109}$ Walker ya indicó que el símbolo podía tener su prototipo en las monedas de cobre de los procuradores romanos de Judea pero sin entrar en análisis alguno al respecto (WALKER, John, A Catalogue of the Muhammadan Coins in the British Museum, vol. II: A Catalogue of the Arab-Byzantine and Post-Reform Umaiyad Coins, British Museum, Londres, 1956, p. 203); ARIZA ARMADA, Almudena, "Signos y símbolos judíos en la moneda omeya oriental" (en preparación). 
de África, en este caso, como en el caso de los feluses con pez, habría que vincularlo al contexto islámico oriental ${ }^{110}$.

De la misma manera que en las primeras emisiones andalusíes se acuñaron algunos de los tipos iconográficos que se habían acuñado ya o se estaban acuñando en oriente en algunas de las cecas omeyas, los judíos del Magreb habrían introducido así en las emisiones que realizaban el símbolo que representaba a la tierra de Israel.

\section{CONCLUSIONES}

Al instalarse la dinastía idrīsí, los judíos ya desempeñaban una significativa labor en la explotación de las minas de plata del Magrib al-Aqșā. Desde los primeros momentos de la expansión idrīsí, condicionada tanto por factores de carácter religioso (la sumisión de las tribus judías, cristianas, animistas y la derrota de los jāriŷ́íes) como económicos (el control de las minas de plata), los judíos acuñaron moneda a nombre del poder político que reconocieron en cada momento, ya fuera la soberanía idrīsí o la de los imām-es jāriŷíes. Probablemente, en ocasiones, lo hicieron como poderes semiindependientes. En ambos casos, grabaron en el numerario una serie de signos y símbolos monetales, que si bien pudieron ser meras marcas de acuñador, también pudieron tener, como creo, una clara connotación de carácter político y/o religioso. De ser cierto, no solamente se trataría de signos y símbolos testimonio de la presencia judía en el Magreb, sino también de símbolos de claro carácter identitario.

${ }^{110}$ ARIZA ARMADA, Almudena, “Aniconismo e iconografía monetal...”, 23-33, 29-30; ARIZA ARMADA, Almudena, "Leyendas monetales, iconografía y legitimación en el Califato Hammūdí. Las emisiones de 'Alī Ibn Ḥammūd del año 408/1017-1018." al-Qanțara, XXV, 1 (2004), 203 - 231. 